\title{
NATURAL RADIONUCLIDES IN WATER USING INDUCTIVELY COUPLED PLASMA - SECTOR FIELD MASS
} SPECTROMETRY

\author{
Elizabeth Teresita Romero Guzmán ${ }^{\mathrm{a}, \mathrm{b}, *,(])}$, José Luis Iturbe García ${ }^{a}$, María de Jesús Marín Allende ${ }^{\mathrm{b}}$, Héctor Hernández \\ Mendoza $^{\text {,dd }}$ and Lázaro Raymundo Reyes Gutiérrez \\ aDepartamento de Química, Gerencia de Ciencias Básicas, Instituto Nacional de Investigaciones Nucleares, Carretera México- \\ Toluca, S/N, La Marquesa Ocoyoacác, Estado de México, México \\ ${ }^{b}$ Laboratorio Nacional de Investigaciones en Forense Nuclear, Gerencia de Tecnología Nuclear, Instituto Nacional de Investigaciones \\ Nucleares. Carretera México-Toluca, S/N, La Marquesa Ocoyoacác, Estado de México, México \\ 'Instituto de Investigación de Zonas Desérticas, Universidad Autónoma de San Luis Potosí, Altair, 20 Colonia del Llano, Z.P. \\ 78377 San Luis Potosí, México \\ ¿Universidad del Centro de México, Capitán Caldera, 75, Colonia Tequixquiapan, Z.P. 78250 San Luis Potosí, México \\ 'Universidad Autónoma Metropolitana, Unidad Lerma, Av. de las Garzas No. 10, Col. El Panteón, Z.P. 52005, Lerma de Villada, \\ Estado de México, México
}

Recebido em 21/06/2021; aceito em 18/10/2021; publicado na web em 18/11/2021

\begin{abstract}
Simultaneous analysis of radionuclides in water had not been performed by mass spectrometry of the magnetic sector. Some international organizations indicate that it is necessary to know the contamination of drinking-water, including radioactive aspects. The novelty of this study was to determine simultaneously radioisotope radium, thorium, uranium and lead stable. Experiments were performed in an accredited laboratory (International Organization for Standardization/International Electrotechnical Commission-7025:2005). The radionuclides of thorium, uranium and some of their descendants were obtained. The reported values are in the range of $7 \mathrm{E}^{-7}-24.28 \mu \mathrm{g} \mathrm{L}^{-1}$. Their presence decreases in the order thorium>uranium>radium in drinking water and uranium $>$ thorium $>$ radium in seawater. These results do not represent any risk to the population because very low concentrations were determined.
\end{abstract}

Keywords: natural radionuclides; water; simultaneous analysis; inductively coupled plasma - sector field.

\section{INTRODUCTION}

The traditional chemical analysis of ions, can reveal whether the substances contained in the water are the result of any human activity or are naturally present in the environment. ${ }^{1,2}$ Water quality also includes the presence of radioactive isotopes. ${ }^{3,4}$ The earth's crust contains radionuclides mainly from the radioactive series of uranium and thorium. The presence of radioactive isotopes means that all descendants of the three natural radioactive chains can be found, that is, ${ }^{238} \mathrm{U},{ }^{235} \mathrm{U}$ and ${ }^{232} \mathrm{Th}$. Where the ${ }^{238} \mathrm{U}$ serie after 8 alpha $(\alpha)$ and 6 beta $\left(\beta^{-}\right)$decays reaches the stable lead $(\mathrm{Pb})$ isotope according to the following notations:

$$
\begin{aligned}
& { }^{238} \mathrm{U} \rightarrow\left(8 \alpha, 6 \beta^{-}\right) \rightarrow{ }^{206} \mathrm{~Pb} \text {, the same applies to the other two radioactive } \\
& \text { series } \\
& { }^{235} \mathrm{U}\left(7 \alpha, 4 \beta^{-}\right) \rightarrow{ }^{207} \mathrm{~Pb} \text { and, } \\
& { }^{232} \mathrm{Th} \rightarrow\left(6 \alpha, 4 \beta^{-}\right) \rightarrow{ }^{208} \mathrm{~Pb}
\end{aligned}
$$

Some of its daughters including ${ }^{226} \mathrm{Ra},{ }^{222} \mathrm{Rn},{ }^{204-208} \mathrm{~Pb},{ }^{210} \mathrm{Po}$, etc. ${ }^{5}$ Moreover, radioactive isotopes such as ${ }^{40} \mathrm{~K}$ and ${ }^{137} \mathrm{Cs}$ are also found in the environment as a result of human activities (nuclear tests and accidents that have occurred in some nuclear reactors) which reach the food chain through the environment mainly the rain and wind. ${ }^{6}$ These radioactive isotopes are found in various systems such as sediments, air, soil, some foods that come from the sea such as fish, surface water and groundwater..$^{7-10}$ In general, the concentrations reported in these systems are in trace level. The natural radioisotopes found in the subsoil can reach the aquatic system through surface leaching of minerals. ${ }^{11}$

*e-mail: elizabeth.romero@inin.gob.mx
In addition, it has been determined that some lead isotopes explain the migration of oil in various areas of some oil-producing countries. ${ }^{12}$ Some authors have considered the presence of ${ }^{226} \mathrm{Ra}$ in drinking water as a possible radiological risk to humans due to its radio-toxicity, which has been determined by nuclear techniques such as gamma and alphaparticle spectrometry, and alpha/beta-counting system., , $^{3,13}$

Natural and artificial radioisotopes have also been found in natural water, food, minerals etc. in some countries through the nuclear analytical techniques mentioned above. ${ }^{13-17}$ However, there are no reported studies on the simultaneous measurement of ${ }^{204} \mathrm{~Pb},{ }^{206} \mathrm{~Pb}$, ${ }^{207} \mathrm{~Pb},{ }^{208} \mathrm{~Pb},{ }^{226} \mathrm{Ra},{ }^{232} \mathrm{Th},{ }^{234} \mathrm{U},{ }^{235} \mathrm{U},{ }^{238} \mathrm{U}$ using the same determination method, always have been used two o more radiometry techniques i. e., inductively coupled plasma - sector field mass spectrometry, and without chemistry separation. Chemical separation was not used because the radionuclides concentration present in water is very low and chemical separations are not efficient at $100 \%$, and this method offers the advantage of making a radionuclides direct determination. Through use of the inductively coupled plasma sector field mass spectrometry technique, radionuclides present in water can be determined simultaneously, which is an advantage of this analytical method.

The determination of naturally occurring radionuclides in the environment by high resolution or sector field inductively coupled plasma mass spectrometry has attracted more interest over the last fifteen years, in comparison with relative to the radiometric techniques, due to improvements in instrumental performance, sample introduction equipment, and sample preparation. ${ }^{18,19}$ With the increase in instrumental sensitivity, it is now possible to measure ultra-trace levels of many radioisotopes, as in this research. In comparison to the inductively coupled plasma mass spectrometry, the inductively 
coupled plasma - sector field mass spectrometry shows more capabilities in terms of resolution (avoid polyatomic interference or effect matrix) and the limit of quantification (few fg per sample).

The ICP-SFMS presents some advantages for element ultra-trace analysis, due to high sensitivity, selectivity and low detection limits, when compared with other analytical techniques. This technique allowed smaller sample size and higher sample throughput, easier sample preparation step and shorter measurement times. ${ }^{20-22}$

In addition, it is important to mention that the inductively coupled plasma - sector field mass spectrometry technique has been accredited under International Organization for Standardization/International Electrotechnical Commission-17025 at the National Laboratory of Nuclear Forensic Investigations in the National Institute of Nuclear Research, for multi-elemental trace and ultra-trace measurements in water.

Nowadays, water has a very important role in the supply of a world population in continuous growth. While demand in recent decades has had difficulties in some regions due to the shortage of the vital liquid or other problems as technology for extraction from underground. Some agencies worldwide as the International Atomic Energy Agency, United Nations, Food and Agriculture Organization, U.S. Environmental Protection Agency, Norma Oficial Mexicana 127SSA-1994 and World Health Organization concerned about the global water situation are currently working on guidelines for establishing reference levels for radioactivity in drinking water including naturally occurring radioactivity consumed by humans, so that there can be water for everyone, mainly in regions of Africa and Latin America Food and Agriculture Organization. ${ }^{23-26}$

Sheppard et al. (2008), measurement analytes in soils and plants (no in water): natural $U$ by neutron activation-delayed neutron counting, ${ }^{230} \mathrm{Th},{ }^{232} \mathrm{Th},{ }^{226} \mathrm{Ra}$ and ${ }^{210} \mathrm{Po}$ by alpha spectroscopy and ${ }^{228} \mathrm{Ra}$ by beta counting. ${ }^{27}$ Romero et al. measured uranium and thorium in surface water, the results showed that there are presence of ${ }^{232} \mathrm{Th},{ }^{234} \mathrm{U},{ }^{235} \mathrm{U}$ and ${ }^{238} \mathrm{U}$ isotopes in surfacewater $\sim 3 \mu \mathrm{g} \mathrm{L}{ }^{-1} \cdot{ }^{28}$ Suárez-Navarro et al. determined specific alpha-emitting radionuclides (uranium, plutonium, thorium and polonium) in water intended for human consumption, the results obtained in five groundwater samples showed how the sum of the alpha-emitter activity values was equivalent to the gross alpha activity. ${ }^{29}$

The objective of this work was to determine the natural radioactive isotopes ( $\mathrm{U}, \mathrm{Th}, \mathrm{Ra}$ and stable $\mathrm{Pb}$ ) present in several aquatic systems in some high areas of the Mexico Center and in the Caribbean seawater, Mexico. It is important to keep in mind that in our country the information on drinking water and seawater from the radiological point of view is very limited or does not exist. In this case, this determination was made using the high resolution mass spectrometry technique. This technique was chosen due to its high sensitivity, short analysis times and allowing multielemental isotopic concentrations.

\section{EXPERIMENTAL}

\section{Materials, reagents and certified reference materials}

All class-A certified volumetric flasks that were used in the preparation were of borosilicate glass, blue graduated, with polypropylene stoppers. They were decontaminated with $10 \% \mathrm{HNO}_{3} \mathrm{v} / \mathrm{v}$ for $24 \mathrm{~h}$ and rinsed with high-purity water.

The solutions were prepared using analytical-grade reagents from Merck (Germany). Deionized Milli-Q water (Resistivity $18.2 \mathrm{M} \Omega \mathrm{cm}$ ) was obtained from a Milli- $\mathrm{Q}_{\circledast}$ Reference (Millipore México). Nitric acid was purified by distillation in a Milestone Duopur (Milestone s.r.l., Italy) sub-boiling system to obtain the hyperpure nitric acid to use during the study. Certified Ar gas (99.999\%) was supplied by
INFRA, S.A. de C.V. México. A multi-elemental reference solution in $2 \% \mathrm{HNO}_{3}$ was used at the National Laboratory of Nuclear Forensic Investigations in the National Institute of Nuclear Research.

\section{Sample collection and preparing}

The collection of all water samples was carried out according to Norma Oficial Mexicana-014-SSA1-1993. ${ }^{30}$ Ten samples were collected, from each point. For this study, we distinguish among three different types of samples: drinking water (DW, DWO), superficial water/groundwater from springs (SUW), and seawater (SEW). The exact locations and sample types are shown in Figure 1.

Drinking water (DW) was obtained from a Toluca City. One was taken directly from the tap that supplied water while the other, once obtained, was treated with an ozone flow for three minutes (DWO). For SUW, the spring was located $15 \mathrm{~km}$ downhill from the Nevado de Toluca, where the spring discharged recharge water from the Toluca Nevado. There were two types of spring samples. The first water sample was collected directly from the spring. The other was collected in a tank that supplied water to the population of San Juan de las Huertas México. This shot came from the spring, which was piped from its origin to the deposit on the shore of the town. Finally, SEW was collected from the surface of the Caribbean Sea close to the shore, in the Riviera Maya, between Cancun and Tulum, México. The depth at which the sample was taken was a meter and a half, where there was no sand. The samples were then acidified with $2 \%$ $\mathrm{HNO}_{3}$, followed by filtration using cellulose nitrate membrane filters (Whatman from GE Healthcare Life Sciences, Proveedor Científico S.A. México) to avoid the particles in suspension.

An aliquot of $45 \mathrm{~mL}$ of each sample was used for the inductively coupled plasma - sector field mass spectrometry analysis according to the Environmental Protection Agency method 3015a. ${ }^{31}$ The analysis of each sample were conducted in triplicates.

\section{Inductively coupled plasma - sector field mass spectrometry analysis}

The isotope measurements of ${ }^{204} \mathrm{~Pb},{ }^{206} \mathrm{~Pb},{ }^{207} \mathrm{~Pb},{ }^{208} \mathrm{~Pb},{ }^{226} \mathrm{Ra},{ }^{232} \mathrm{Th}$, ${ }^{234} \mathrm{U},{ }^{235} \mathrm{U}$, and ${ }^{238} \mathrm{U}$ were carried out directly in the LANAFONU-ININ at a temperature of $20^{\circ} \mathrm{C}$ and a humity of 30-40\%. Mass spectrometry laboratory at LANAFONU is equipped with Thermo Element XR High-Resolution ICP-Mass Spectrometer or Inductively Coupled Plasma of Sector Field Mass Spectrometer and has three operation modes: Low Resolution (LR), Medium Resolution (MR), and High Resolution (HR). During the inductively coupled plasma - sector field mass spectrometry analysis, the radionuclides were measured in Low Resolution $(\mathrm{m} / \Delta \mathrm{m}=300)$. The time of analysis was around 7 min per sample ( $\mathrm{n}=30$ measurements for each isotope).

All methods used for water analysis were carried out within a quality system certified (ISO/IEC 17025:2005) research laboratory in which methods were developed and validated and underwent routine quality assurance processes. LANAFONU-ININ was accredited as an assay laboratory under the NMX-EC-17025-IMNC-2006 (ISO/ IEC 17025:2005) standard. General requirements for the competence of testing and calibration laboratories, for the research discipline (accredited ICP-SFMS technique; validation procedure number PL.VL.LFN05-2018) by the entidad mexicana de acreditación (ema), accreditation number INV-0009-015/19 NMX-EC-17025IMNC-2006 (ISO/IEC17025:2005) from 2019/11/21, reference number: 18INV0016.

Within the adjustment made with respect to the physical accessories equipment, the best combination in terms of sensitivity, stability, and sample consumption, for a multi-elemental solution of 


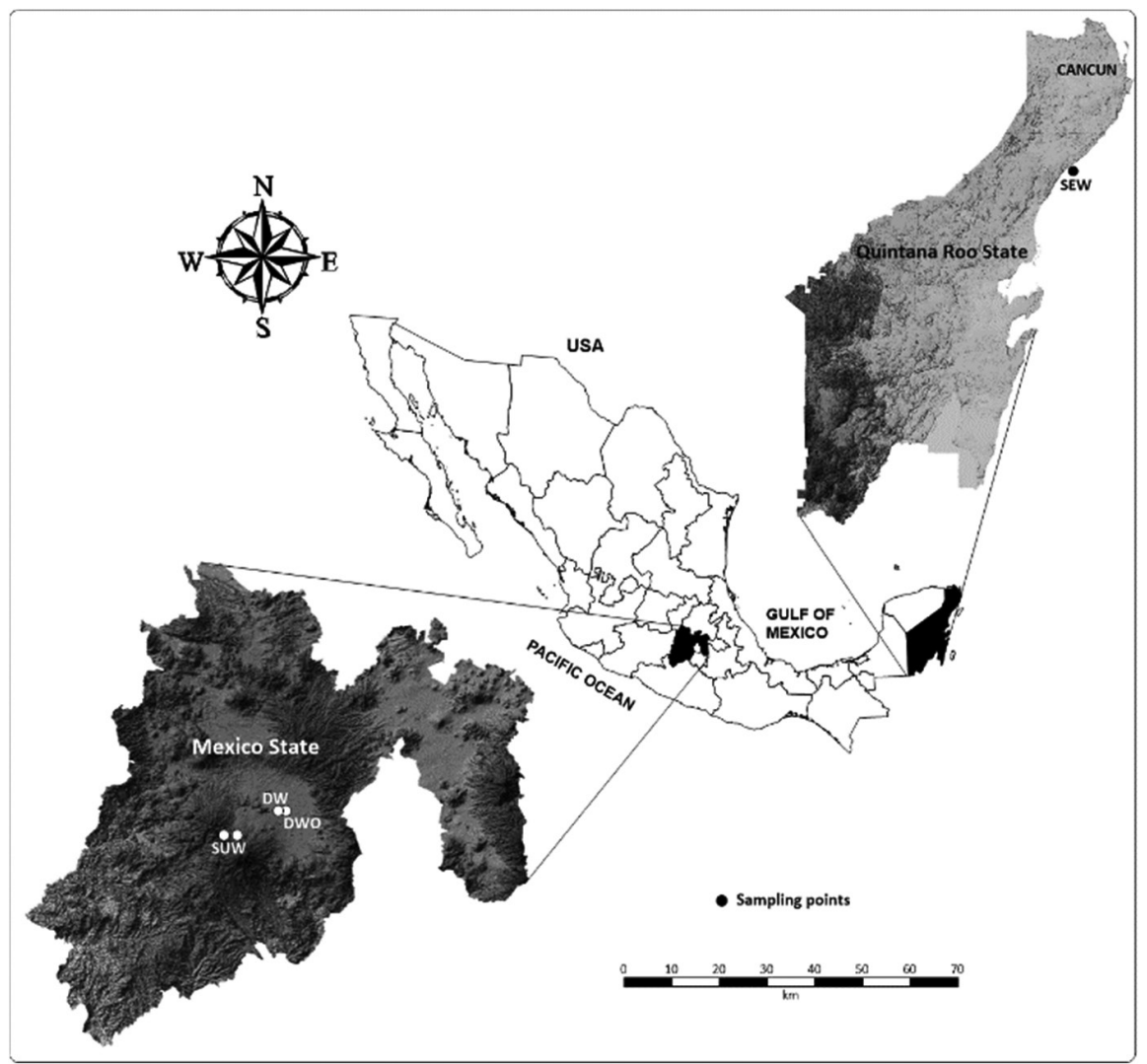

Figure 1. Location of sampling points in Mexico

$1 \mu \mathrm{g} \mathrm{\textrm {L } ^ { - 1 }}$ in $2 \%$ nitric acid resulted, the inductively coupled plasma - sector field mass spectrometry worked with a jet cone as a sample cone, a high-efficiency $\mathrm{H}$ skimmer, a micromist nebulizer of $400 \mu \mathrm{L}$ $\mathrm{min}^{-1}$, and a quartz injector of $1.7 \mathrm{~mm}$ in diameter.

Before measurement of the ${ }^{204} \mathrm{~Pb},{ }^{206} \mathrm{~Pb},{ }^{207} \mathrm{~Pb},{ }^{208} \mathrm{~Pb},{ }^{226} \mathrm{Ra},{ }^{232} \mathrm{Th}$, ${ }^{234} \mathrm{U},{ }^{235} \mathrm{U}$, and ${ }^{238} \mathrm{U}$ isotopes, the inductively coupled plasma - sector field mass spectrometry was tuned and optimized. The instrument was optimized daily with respect to the torch position, sample, and auxiliary gas flow, to reach a maximum counting rate and a stable signal. Table 1 summarizes the chosen instrumental parameters in order to gain sensitivity and improve counting statistics for the ${ }^{204} \mathrm{~Pb}$, ${ }^{206} \mathrm{~Pb},{ }^{207} \mathrm{~Pb},{ }^{208} \mathrm{~Pb},{ }^{226} \mathrm{Ra},{ }^{232} \mathrm{Th},{ }^{234} \mathrm{U},{ }^{235} \mathrm{U}$, and ${ }^{238} \mathrm{U}$ isotope measures. Then, mass offset was performed by using the $10 \mu \mathrm{g} \mathrm{L}^{-1}$ certified multi-elemental standard solution (Thorium $2 \% \mathrm{HNO}_{3} 1,000 \mu \mathrm{g} \mathrm{mL}^{-1}$ (999 $\left.\mu \mathrm{g} \mathrm{mL}^{-1} \pm 5 \mu \mathrm{g} \mathrm{mL}^{-1}\right)$ CLTH2-2Y/CL9-159THY; SPEC CertiPrep. Lead $2 \% \mathrm{HNO}_{3} 1,000 \mu \mathrm{g} \mathrm{mL}^{-1}\left(999 \mu \mathrm{g} \mathrm{mL}^{-1} \pm 5 \mu \mathrm{g} \mathrm{mL}^{-1}\right)$ CLPB2-2M/ CL7-81PBM; SPEC CertiPrep.. Uranium $2 \% \mathrm{HNO}_{3} 1,000 \mu \mathrm{g} \mathrm{mL}^{-1}$ $\left(1,001 \mu \mathrm{g} \mathrm{mL}^{-1} \pm 5 \mu \mathrm{g} \mathrm{mL}^{-1}\right)$, CLU2-2Y/CL9-29UY; SPEC CertiPrep. Indium $2 \% \mathrm{HNO}_{3} 10 \mu \mathrm{g} \mathrm{mL}^{-1}\left(10 \mu \mathrm{g} \mathrm{mL}^{-1} \pm 0.05 \mu \mathrm{g} \mathrm{mL}^{-1}\right) \mathrm{CLI} 2-1 \mathrm{AY} /$ CL9-132INY; SPEC CertiPrep.). An aliquot of $1 \mu \mathrm{g} \mathrm{L}^{-1}$ of an ${ }^{115} \mathrm{In}$ external standard solution (Merck, Germany) was added during the measurements to monitor the instrumental stability. The Standard Reference Material $^{\circledR}$ 1640a Trace Elements in Natural Water ${ }^{32}$ was used. A ${ }^{226} \mathrm{Ra}$ standard solution $(282.28 \mathrm{~Bq})$ was added to $40 \mathrm{~mL}$ of a $2 \% \mathrm{HNO}_{3}$ solution. For the inductively coupled plasma - sector field mass spectrometry measurements, the samples were aspirated via the nebulizer. The element ${ }^{115} \mathrm{In}$ can be used as an internal and external standard $\left(1 \mu \mathrm{g} \mathrm{L}^{-1}\right)$. The inductively coupled plasma - sector field mass spectrometry technique was accredited under ISO-17205. More specifically, the accreditation focuses on the measurement of radionuclides using it. In addition, to ensure that the measurement was correct and to start the scan in LR, we had to check the signal stability. If the performance was satisfying, at least $1,000,000 \mathrm{cps}$ for
${ }^{115} \mathrm{In}$, like the external standard, was measured with $1 \mu \mathrm{g} \mathrm{L}^{-1}$ at this $\mathrm{m} / \mathrm{z}$ for the inductively coupled plasma - sector field mass spectrometry. Finally, we optimized the measurement using three masses, $\mathrm{m} / \mathrm{z}$, at low $\left(\mathrm{m} / \mathrm{z}={ }^{7} \mathrm{Li}\right)$, medium $\left(\mathrm{m} / \mathrm{z}={ }^{115} \mathrm{In}\right)$, and high $\left(\mathrm{m} / \mathrm{z}={ }^{238} \mathrm{U}\right)$.

The inductively coupled plasma - sector field mass spectrometry device whereby samples were analysed was previously calibrated with $0.1,0.5,1,5,10$ and $20 \mu \mathrm{g} \mathrm{L}^{-1}$ of lead, radium, thorium and uranium concentrations. Then, we added $1 \mu \mathrm{g} \mathrm{L}^{-1}$ of ${ }^{115} \mathrm{In}$ standard (Assurance SPEX CertiPrep) and $2 \mathrm{~mL}$ of hyperpure nitric acid and filled volumetric flasks with up to $100 \mathrm{~mL}$ of deionized Milli-Q water. A total of $10 \mathrm{~mL}$ of each standard was transferred to plastic test tubes to proceed with the analysis.

The mass calibration was performed using a certified multi-element or tuning solution XXIII of $1 \mu \mathrm{g} \mathrm{L}^{-1}$ (Ba, B, Co, Fe, Ga, In, K, Li, Lu, $\mathrm{Na}, \mathrm{Rh}, \mathrm{Sc}, \mathrm{Y}, \mathrm{Tl}$, and U, Merck, Germany) traceable to the National Institute of Standards and Technology, United States of America.

The sequence used was edited to read the samples includes blanks, standards, samples and quality controls. The results presented in this work undergo a detailed process: from checking the background, which is subsequently subtracted from the readings of all the measured samples (standards, samples, quality controls), checking calibration curves, checking the stability of the equipment to through the measurement of a concentration standard known as quality control measured every 6 samples in this case.

Raw data from inductively coupled plasma - sector field mass spectrometry measurements were evaluated using Microsoft Excel®. Additionally, the entire data set was checked to present the results reported here.

\section{Statistical tests}

All statistical analyses, mean, standard deviation were obtained using Excel. The limits of detection obtained in ICP-SFMS for each 
element were obtained. LODs were calculated from reagent blanks $(\mathrm{n}=10)$. Accuracy for the proposed method was evaluated using the Standard Reference Material ${ }^{\circledR}$ 1640a Trace Elements in Natural Water. $^{33}$

\section{RESULTS AND DISCUSSION}

\section{Optimization to isotopes measured}

To tune the system on the selected isotopes $\left({ }^{7} \mathrm{Li},{ }^{115} \mathrm{In}\right.$, and $\left.{ }^{238} \mathrm{U}\right)$, a multi-element solution with the elements $\mathrm{Li}, \mathrm{B}, \mathrm{Na}, \mathrm{Sc}, \mathrm{Co}, \mathrm{Fe}, \mathrm{Zn}$, Y, Rh, In, Ba, Lu, Tl, and U at $1 \mu \mathrm{g} \mathrm{L}^{-1}$ (Merck Tune solution) was introduced. The Low Resolution mode was suitable for measuring isotopes such as $\mathrm{Pb}, \mathrm{Ra}$, Th and $\mathrm{U}$ because these radionuclides have low interferences with other elements. For this reason, the measurements were made only in Low Resolution mode and it was not necessary to tune in Medium Resolution and High Resolution, Figure 2.

The concentration of ${ }^{115} \mathrm{In}\left(1 \mu \mathrm{g} \mathrm{L}^{-1}\right)$ is a requirement of inductively coupled plasma - sector field mass spectrometry for method optimization. For this reason, this concentration was used. The performance of the signal stability and intensity was satisfactory because it obtained at least $1,127,580 \mathrm{cps} \pm 37,953 \mathrm{cps}$ for ${ }^{115} \mathrm{In}$ $\left(1 \mu \mathrm{g} \mathrm{L}^{-1}\right)$ and at least $1,411,256 \mathrm{cps} \pm 43,854 \mathrm{cps}$ for ${ }^{238} \mathrm{U}$. In this case, for ${ }^{7} \mathrm{Li}$, the Relative Standard Deviation was $=1.8797 \%$; for ${ }^{115} \mathrm{In}$, the Relative Standard Deviation $=1.3250 \%$, while for ${ }^{238} \mathrm{U}$, the Relative Standard Deviation $=0.9095 \%$ with $n=100$ measurements. This indicates that the signal stability and intensity were optimal (Relative Standard Deviation $\leq 2 \%$ ) and that the radionuclide measurements were correct. The internal standard concentration of ${ }^{115} \mathrm{In}$ used was $1 \mu \mathrm{g} \mathrm{L}^{-1}$ for Low Resolution.

With the data obtained from the inductively coupled plasma
- sector field mass spectrometry analysis, the multi-elemental calibration curves (lead, radium, thorium and uranium) using certified reference materials were elaborated, considering the same ionization potentials, we using counting, analog and Faraday mode to measure these isotopes. It appreciated that the values correlate closely to the unit in all cases $\left({ }^{204} \mathrm{~Pb}\left(\mathrm{y}=10158 \mathrm{x}+8954.4 ; \mathrm{R}^{2}=0.9996\right),{ }^{206} \mathrm{~Pb}\right.$ $\left(y=187843 \mathrm{x}+131937 ; \mathrm{R}^{2}=0.9999\right),{ }^{207} \mathrm{~Pb}(\mathrm{y}=160586 \mathrm{x}+100703$; $\left.\mathrm{R}^{2}=1.0000\right),{ }^{208} \mathrm{~Pb}\left(\mathrm{y}=394158 \mathrm{x}+234805 ; \mathrm{R}^{2}=0.9999\right),{ }^{226} \mathrm{Ra}$ $\left(\mathrm{y}=2.1937 \mathrm{x}+0.6715 ; \mathrm{R}^{2}=0.9998\right),{ }^{232} \mathrm{Th}(\mathrm{y}=573351 \mathrm{x}-356877$; $\left.\mathrm{R}^{2}=0.9998\right),{ }^{234} \mathrm{U} \quad\left(\mathrm{y}=46.905 \mathrm{x}+8.337 ; \mathrm{R}^{2}=0.9999\right),{ }^{235} \mathrm{U}$ $\left(y=6140.3 x+1091.4 ; R^{2}=0.9999\right),{ }^{238} U(y=846631 x+150482$; $\left.\mathrm{R}^{2}=0.9999\right)$ ). With this information, the measurements of the radioisotopes and lead were supported.

We paid attention to peak tailing, matrix effect, and polyatomic and isobaric effect during the analysis by inductively coupled plasma - sector field mass spectrometry. The results were obtained taking into consideration the integration window, it was around $20 \%$ of the peak center to avoid tailing effects, the method mass offset was determined to further decrease any possibility of interferences. The instrument parameters were optimized to avoid this effect from peak tailing, matrix, and polyatomic effect. In addition, the residual analysis of the calibration curves verified that the relationship between the concentration and intensity variables is linear, so the concentrations are correct. The spectra did not show any effect from peak tailing or polyatomic and isobaric interference during the analysis by inductively coupled plasma - sector field mass spectrometry. Also, the use of matrix matched reference materials probed that matrix effects were not significative.

LODs were calculated from reagent blanks $(n=10)$. The results obtained for the limit of detection (LOD) were for $\mathrm{Pb}\left(0.0206 \pm 0.001 \mathrm{ng} \mathrm{L}^{-1}\right),{ }^{\text {total }} \mathrm{U}\left(0.1396 \pm 0.001 \mathrm{ng} \mathrm{L}^{-1}\right), \mathrm{Th}$ $\left(0.1266 \pm 0.002 \mathrm{ng} \mathrm{L}^{-1}\right)$ and $\mathrm{Ra}\left(0.0236 \pm 0.0004 \mathrm{ng} \mathrm{L}^{-1}\right)$.
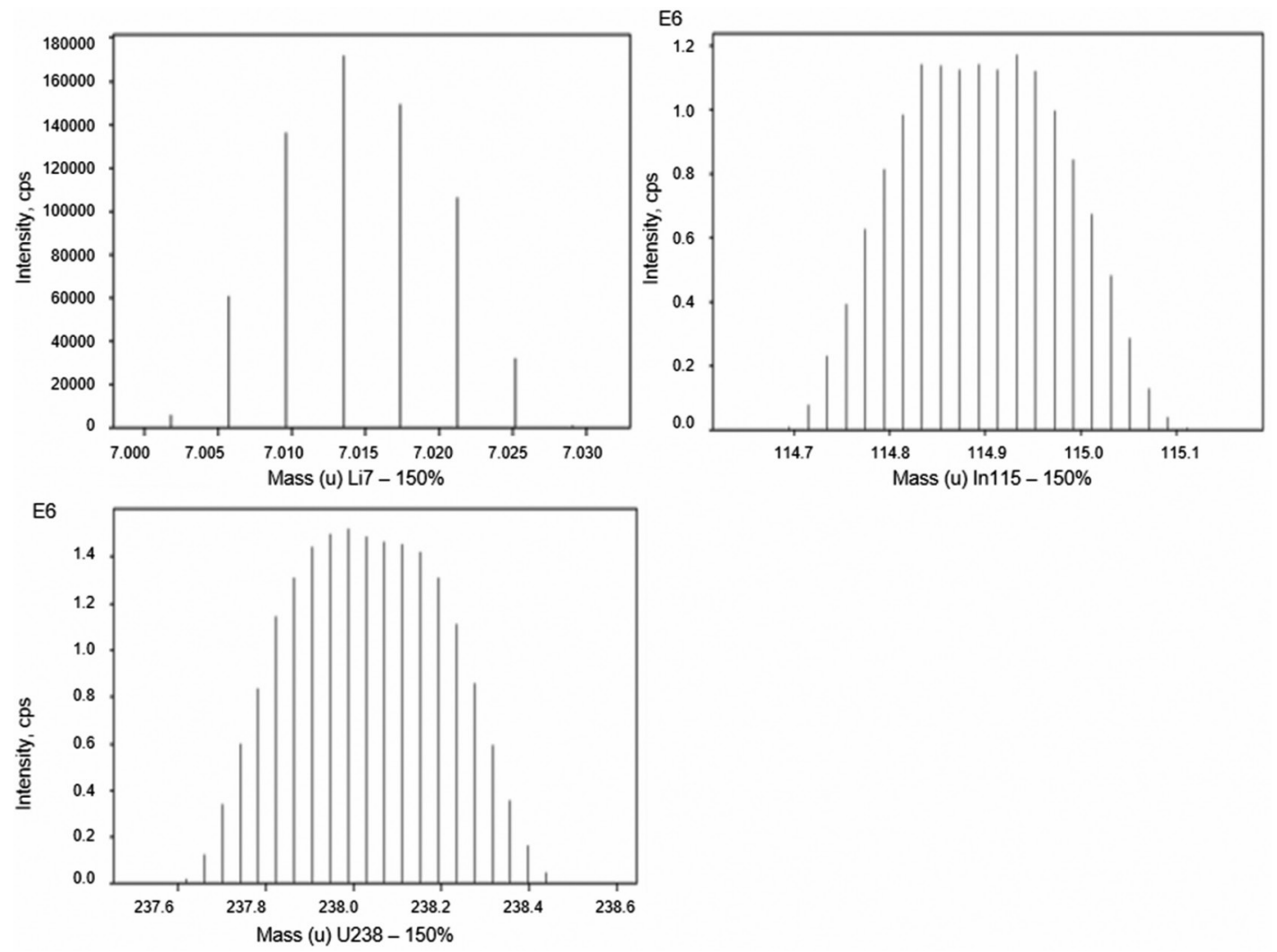

Figure 2. LR mass spectra for ${ }^{7} \mathrm{Li},{ }^{115}$ In and ${ }^{238} \mathrm{U}$ isotopes 


\section{Isotope qualitative determination}

Figure 3 shows the qualitative inductively coupled plasma - sector field spectra of the analysed lead, radium, thorium and uranium isotopes. Each spectrum shows the mass from $\mathrm{m} / \mathrm{z}=203$ to $\mathrm{m} / \mathrm{z}=240$. This shows the isotopes of the analysed radionuclides and lead and indicates their different proportions in abundance $\left({ }^{204} \mathrm{~Pb}=1.4\right.$, ${ }^{206} \mathrm{~Pb}=24.1,{ }^{207} \mathrm{~Pb}=22.1,{ }^{208} \mathrm{~Pb}=52.4,{ }^{226} \mathrm{Ra},{ }^{232} \mathrm{Th}=99.98,{ }^{234} \mathrm{U}=0.0054$, ${ }^{235} \mathrm{U}=0.7204,{ }^{238} \mathrm{U}=99.27$ abundance percentages) ${ }^{34}$ Table 1 shows the abundances of the isotopes analyzed together with the standards used and their theoretical value, it can be seen that they are radionuclides in a natural abundance as it should be expected.

For the samples analysed, it can be seen that lead is the major element, followed by uranium in the SEW. Generally, uranium and thorium vary little among the other types of water: DW, DWO, and SUW.

\section{Isotope quantitative determination}

Lead: $\mathrm{Pb}$, is one of the most widely studied metals in environmental sciences due to its toxicity and widespread use. ${ }^{35,36}$ The four lead isotopes $\left({ }^{204} \mathrm{~Pb},{ }^{206} \mathrm{~Pb},{ }^{207} \mathrm{~Pb}\right.$ and $\left.{ }^{208} \mathrm{~Pb}\right)$ have been present since the formation of the earth, so their isotopic composition in a given region and at a given moment depends on the concentration of lead at that time and the amount of lead that has been produced as a result of the radioactive decay of primordial ${ }^{238} \mathrm{U}$ and ${ }^{232} \mathrm{Th}$ radionuclides. These primordial radionuclides include isotopes of thorium, radium, polonium, lead, etc. ${ }^{15,17,35-38}$ Theoretically, it is also possible to determine the low-abundance isotope ${ }^{204} \mathrm{~Pb}$ on an inductively coupled plasma - sector field mass spectrometry. ${ }^{35}$ With respect to the concentration of lead isotopes, Figure 4, it can be seen that lead is present up to $\sim 9.65-15.19 \mu \mathrm{g} \mathrm{L}^{-1}$ for ${ }^{204} \mathrm{~Pb}, \sim 6.29-12.39 \mu \mathrm{g} \mathrm{L}^{-1}$ for ${ }^{206} \mathrm{~Pb} \sim 5.27-8.87 \mu \mathrm{g} \mathrm{L}^{-1}$ for ${ }^{207} \mathrm{~Pb}$ and $\sim 14.07-24.28 \mu \mathrm{g} \mathrm{L}^{-1}$ for ${ }^{208} \mathrm{~Pb}$.

Radium: $\mathrm{Ra}$, the radium qualitative and quantitative determination was done. The first goal was qualitative detecting the radio signal at the $\mathrm{m} / \mathrm{z}=226$ in the mass spectrum of ICP-SFMS, which was achieved. In this case, the radium peak shape was satisfactory in the spectrum displayed and the signals obtained in counting mode was displayed in colour blue. The ${ }^{226} \mathrm{Ra}$ isotope was the dominant radium form. In the case of ${ }^{226} \mathrm{Ra}$, the concentration ranged from $0.000125 \mu \mathrm{g} \mathrm{L}^{-1}$ to $0.00045 \mu \mathrm{g} \mathrm{L}^{-1}$, Figure 5 .

Thorium: Th, in the case of thorium isotope in water, ${ }^{232} \mathrm{Th}$ was the dominant form in all water samples, Figure 6 . Its concentration ranged from $\sim 16.36-17.51 \mu \mathrm{g} \mathrm{L}{ }^{-1}$ for ${ }^{232} \mathrm{Th}$.

Table 1. Proportions in abundance of the analyzed radionuclides

\begin{tabular}{|c|c|c|c|c|c|c|c|c|}
\hline & ${ }^{204} \mathrm{~Pb}$ & ${ }^{206} \mathrm{~Pb}$ & ${ }^{207} \mathrm{~Pb}$ & ${ }^{208} \mathrm{~Pb}$ & ${ }^{232} \mathrm{Th}$ & ${ }^{234} \mathrm{U}$ & ${ }^{235} \mathrm{U}$ & ${ }^{238} \mathrm{U}$ \\
\hline Theoric value ${ }^{34}$ & 1.4 & 24.1 & 22.1 & 52.4 & 99.98 & 0.0054 & 0.7204 & 99.2745 \\
\hline Standard value & 1.4 & 24.1 & 22.1 & 52.4 & 99.99 & 0.0050 & 0.7200 & 99.2750 \\
\hline DW & 1.4 & 26.8 & 19.2 & 52.5 & 99.99 & 0.0052 & 0.7000 & 99.2900 \\
\hline DWO & 1.4 & 23.9 & 20.6 & 54.1 & 99.99 & 0.0050 & 0.7120 & 99.2800 \\
\hline SUW & 1.4 & 24.3 & 21.2 & 53.3 & 99.99 & 0.0053 & 0.7035 & 99.2935 \\
\hline SEW & 1.4 & 24.1 & 20.3 & 54.1 & 99.99 & 0.0051 & 0.7245 & 99.2745 \\
\hline
\end{tabular}
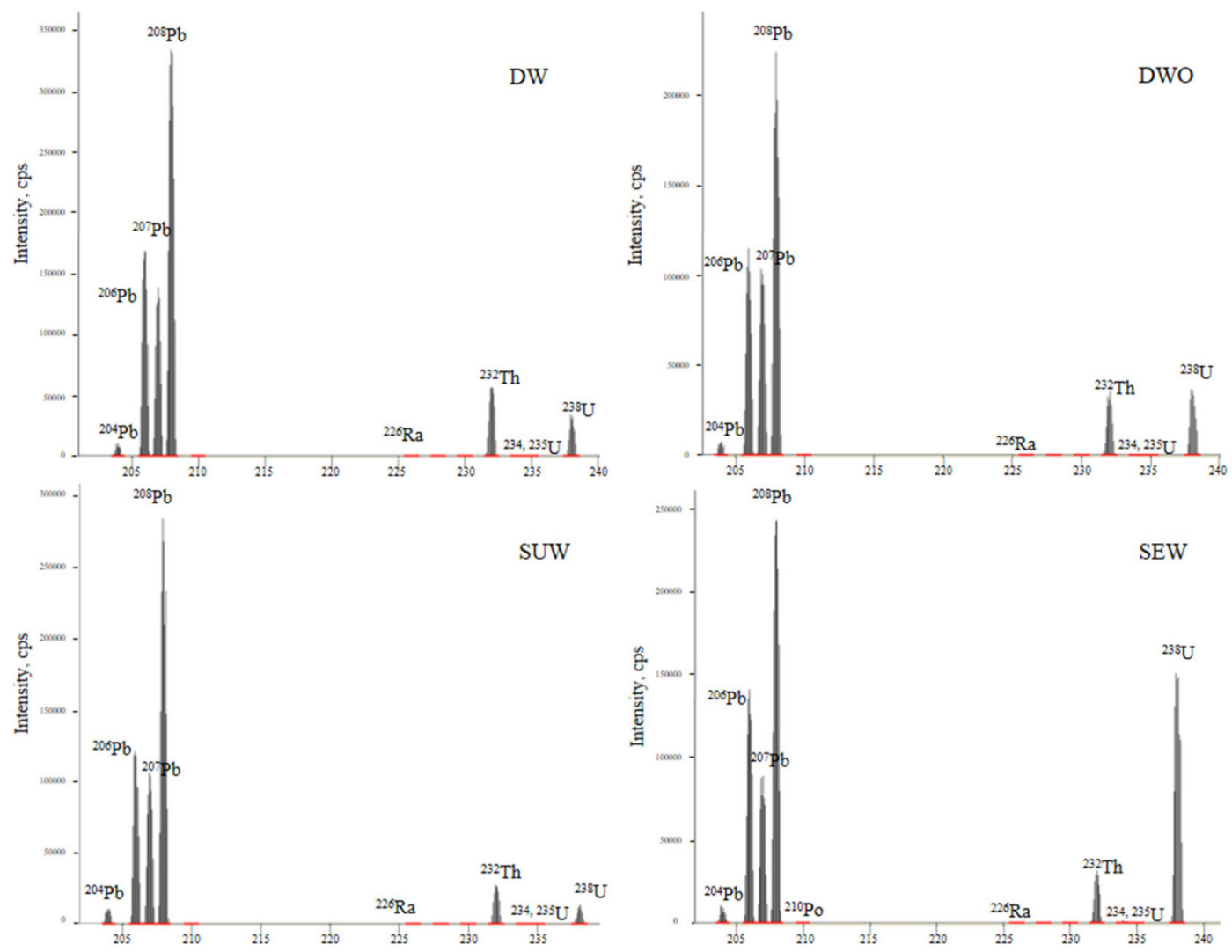

Figure 3. ICP-SFMS spectra of the isotopes analysed in all samples 

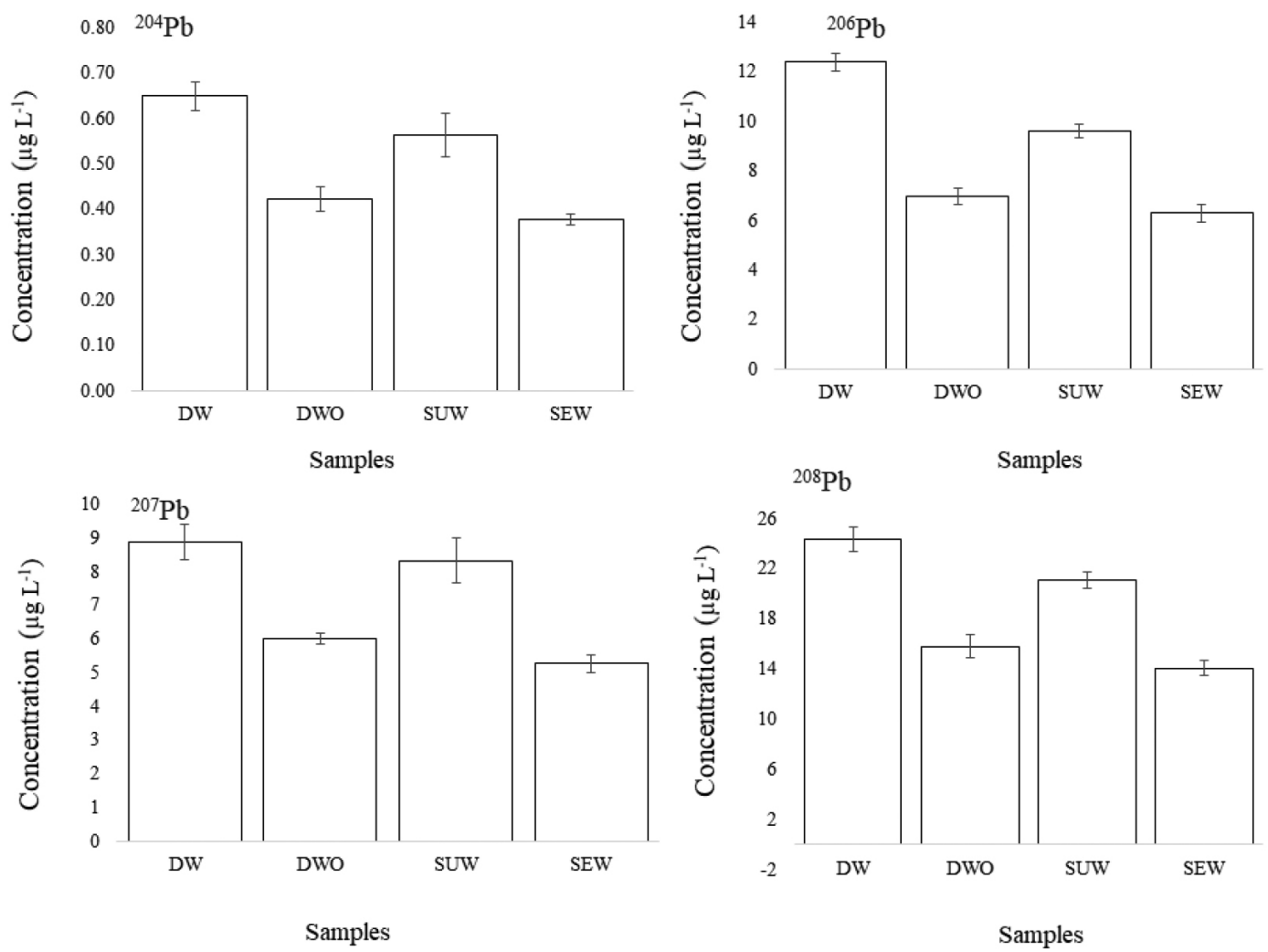

Figure 4. Lead isotopes concentration in water samples

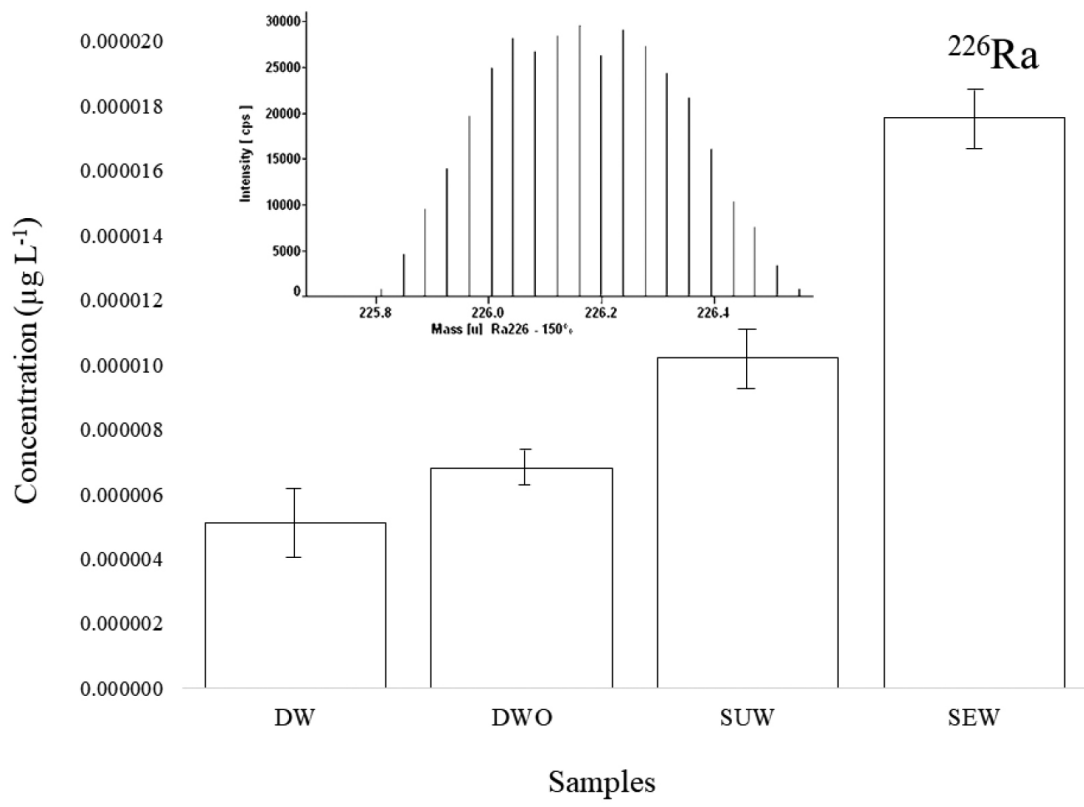

Figure 5. ${ }^{226} \mathrm{Ra}$ isotope concentration in water samples

Uranium: U, Figure 7 shows the uranium isotopes found in water samples. Their concentration ranges are as follows: for ${ }^{234} \mathrm{U} \sim 0.000007-0.00021 \mu \mathrm{g} \mathrm{L}{ }^{-1}$, for ${ }^{235} \mathrm{U} \sim 0.0009-0.0268 \mu \mathrm{g} \mathrm{L}{ }^{-1}$ and for ${ }^{238} \mathrm{U} \sim 0.1244-3.6974 \mu \mathrm{g} \mathrm{\textrm {L } ^ { - 1 }}$. It can see concordance with its natural abundance of them. ${ }^{34}$ We determined total $\mathrm{U}$, then the slopes of the curves varied with the isotopic abundance of each isotope. For a given concentration of $U$ the count rate at 238 was much higher than 234 or 235 .

Uranium and other radionuclides are found naturally in water across Mexico. In this case, uranium and thorium were the most dominant elements present in water samples. The SEW sampled exhibited the highest concentrations of uranium radionuclide, while DW exhibited the highest concentration of thorium radionuclide. Sarin et al. (1992) reported ${ }^{17}$ that thorium has short residence times in ocean water.

In terms of measuring specific radionuclides, if either of the gross alpha screening levels is exceeded, the specific radionuclides should be identified and their individual activity or concentrations measured. ${ }^{23}$ In this case, the presence of natural radionuclides in water according to their percentage decreases in the following order uranium $>$ thorium $>$ radium for seawater and thorium $>$ uranium $>$ radium for drinking water. Therefore, the radionuclides that contribute 


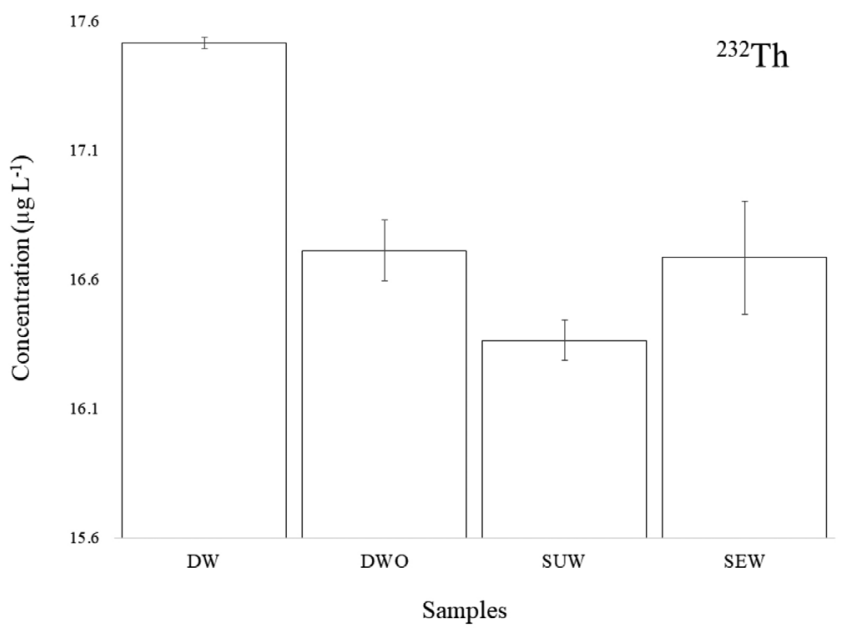

Figure 6. ${ }^{232}$ Th isotope concentration in water samples

individually to the emission of gross alpha radioactivity are the elements mentioned above.

Inductively coupled plasma - sector field mass spectrometry has gained interest in radiochemistry as a method for determining longlived radioisotopes, Figure $8 ; ;^{39,40}$ however, it is also an alternative for measuring those short-lived radionuclides simultaneously. It is one of the most suitable methods for the isotopic analysis of actinides at ultra-trace concentration levels due to its high sensitivity, good accuracy and precision, and quite simple sample preparation procedure. On the other hand, the major disadvantage of the application of radioanalytical methods for the determination of radionuclides relates to the counting period time, which can take from a few days to several weeks depending on the sensitivity required (alpha spectrometry).

Simultaneous measurement was performed without radiochemical separation because the separation processes reduces the radionuclide
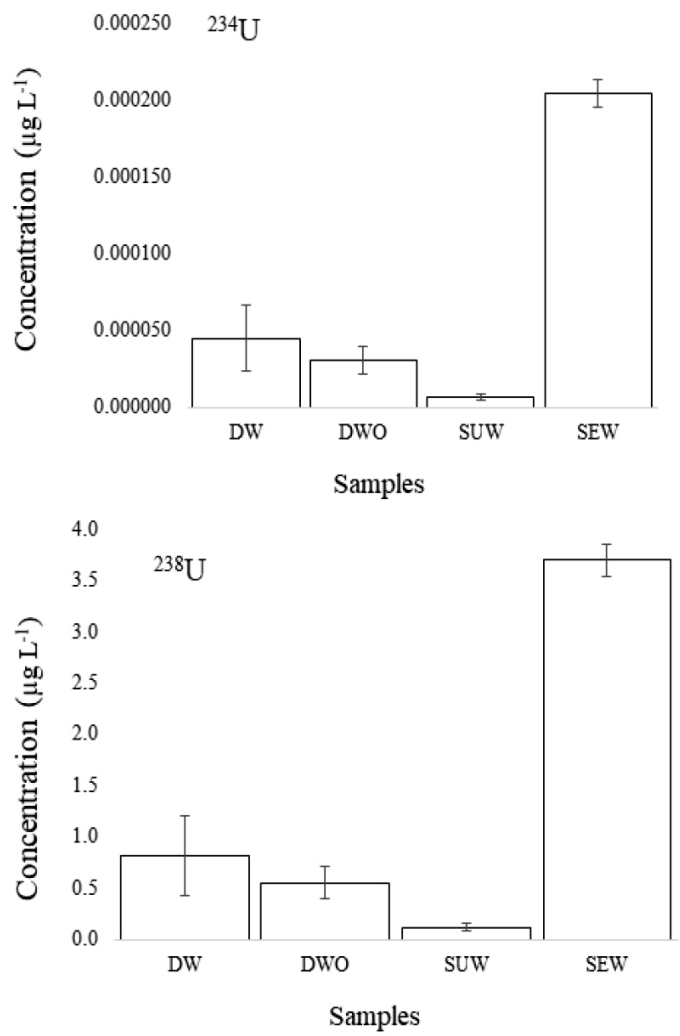

Figure 7. Concentration of the ${ }^{234} U,{ }^{235} U$ and ${ }^{238} U$ isotopes in water samples recovery percentage, taking advantage of the increase in instrumental sensitivity and the ionization potential of the analyzed isotopic elements to measure ultra-trace levels ( $\mathrm{ng}, \mathrm{fg}$ ) of many radioisotopes, including those with half-lives between 1 and 1000 years, without requiring very complex sample pre-concentration sequences. ${ }^{18,19}$ Irradiation with thermal neutrons and potential radiological risk was avoided and the time required for the measurement of multiradionuclides by inductively coupled plasma - sector field mass spectrometry was one day, which is significantly shorter than any radioanalytical protocol currently available.

It is very important to note that the ionization potential in the plasma at $7500 \mathrm{~K}$ is $7.42 \mathrm{eV}$ for $\mathrm{Pb}$ (ionization degree $94 \%$ ), 5.28 $\mathrm{eV}$ for $\mathrm{Ra}$ (ionization degree $100 \%), 6.31 \mathrm{eV}$ for Th (ionization degree $99 \%$ ) and $6.19 \mathrm{eV}$ for $\mathrm{U}$ (ionization degree 99\%); the Ra radioisotope occurs as part of the uranium-series, and it is important Naturally Occurring Radionuclides in Materials, as well as uranium and thorium, which were studied ${ }^{41}$ For these reasons, it is clear that the uranium isotope with the longest half-life was the main mass contributor.

Therefore, due to their great ionization potential and their energetic of ion formation lead $\left(715.6 \mathrm{~kJ} \mathrm{~mol}^{-1}\right)$, radium $\left(509.3 \mathrm{~kJ} \mathrm{~mol}^{-1}\right)$, thorium $\left(608.5 \mathrm{~kJ} \mathrm{~mol}^{-1}\right)$, and uranium $\left(597.6 \mathrm{~kJ} \mathrm{~mol}^{-1}\right),{ }^{41,42}$ it was possible to identify them using this technique without chemical separation.

According to the Comisión Nacional del Agua in México, it is necessary to develop new methods for simultaneous radionuclides measurement in water using inductively coupled plasma - sector field mass spectrometry, for the evaluation and safety of drinking water, and to avoid possible damage to health due to non-compliance with the national regulations ("Mexican standards for drinking water"); it is also necessary to identify which radionuclide contributes most to the alpha radiation, which is a radioactive parameter of drinking water. The inductively coupled plasma - sector field mass spectrometry technique allows measured in a simultaneous way the

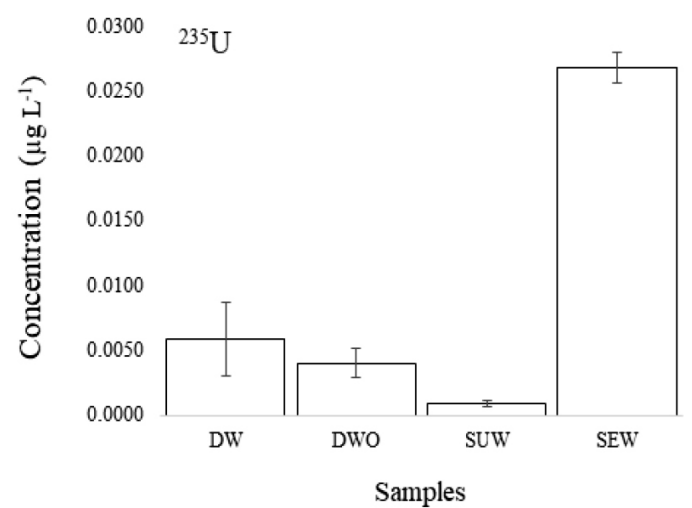




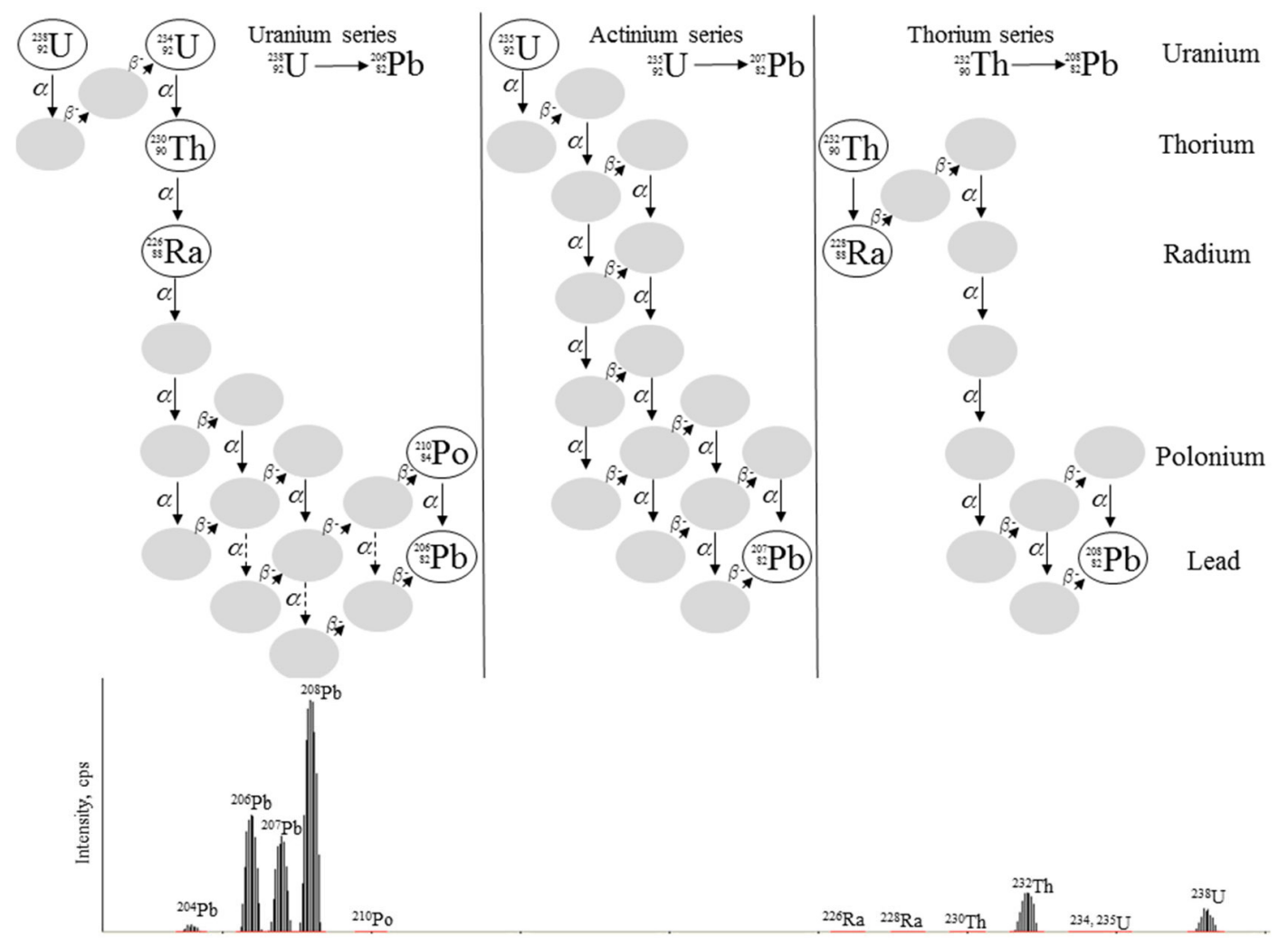

Figure 8. Natural radionuclides determine in the uranium, actinium and thorium series in water samples

alpha emitters in comparison with alpha spectrometry technique, in which it is necessary to perform the different individual operations (pre-concentration, separation, and radionuclide purification); other spectrometric techniques can measure only the most abundant radionuclides and their concentrations as total elements. On the other hand, this new method could be of interest to the Mexican government, especially for the radioactive parameter analysis of underground water wells in Mexico or throughout the world.

\section{CONCLUSIONS}

Natural radionuclides (uranium, thorium and radium isotopes) and stable lead were measured in water samples from Mexico using a refined detection technique, in simultaneous mode, with short analysis times and ultra-trace levels of concentration and without previous chemical separations.

${ }^{238} \mathrm{U}$ and ${ }^{232} \mathrm{Th}$ were the dominant isotopes in all water samples. High uranium presence was found in seawater, while the highest concentration of thorium was found in drinking water. The presence of natural radionuclides (gross alpha emitters) in water according to their percentage decreased in the order of $U>\mathrm{Th}>\mathrm{Ra}$ for seawater and the order $\mathrm{Th}>\mathrm{U}>\mathrm{Ra}$ for drinking water.

According to the natural abundance, it can be seen that the radionuclides analyzed in the water reach values very close to the theoretical values, which supports that the analysis was correctly carried out and the values of the concentration of reliable isotopes.

Sector field inductively coupled plasma - mass spectrometry is one of the most efficient techniques for the analysis of selected radionuclides at ultra-trace levels. Accreditation is now widely used to attest for laboratory competence; Laboratorio Nacional de Investigaciones en Forense Nuclear, which includes inductively coupled plasma - sector field mass spectrometry, has this accreditation.
There is no potential risk to human health in the region of our country where the study was conducted. This is because drinking water for seawater is considered safe due to low concentration levels of radionuclides in the samples analyzed. Therefore, it should not be a cause for concern with respect to its consumption and marine life.

\section{ACKNOWLEDGEMENTS}

The authors are grateful to the CONACYT-2014, Modalidad A. Establecimiento de Laboratorio Nacional de Investigaciones en Forense Nuclear (Project No. 232762) for financial support and Project Comisión Nacional del agua-CONACYT No. 284147. To Eng. Fortunato Aguilar Hernández, M. en C. Manuel Alejandro Pérez Brito, Ing. Israel Bolaños Gutiérrez, Ing. Adrián Reyes del Valle and I.Q.B. Elizabeth Alba Sánchez for their help.

\section{REFERENCES}

1. Roşca, O. M.; Dippong, T.; Marian, M.; Mihali, C.; Mihalescu, L.; Hoaghia, M. A.; Jelea, M.; Environ. Res. 2020, 182, 109136.

2. Simate, G. S.; Iyuke, S. E.; Ndlovu, S.; Heydenrych, M.; Walubita, L. F.; Environ. Int. 2012, 39, 38.

3. Lytle, D. A.; Sorg, T.; Wang, L.; Chen, A.; Water Res. 2014, 50, 396.

4. Manjón, G.; Mantero, J.; Vioque, I.; Díaz-Francés, I.; Galván, J. A.; Chakiri, S.; Choukri, A.; García-Tenorio, R.; Journal of Sustainable Mining 2019, 18, 45.

5. Iturbe-García, J. L.; Fundamentos de Radioquímica, UAEM: Mexico, 2001, Capítulo XVI - Radiactividad natural y artificial, p. 264.

6. Querfeld, R.; Pasi, A. E.; Shozugawa, K.; Vockenhuber, C.; Synal, H. A.; Steier, P.; Steinhauser, G.; Science of the Total Environment 2019, 689, 451.

7. Milenkovic, B.; Stajic, J. M.; Stojic, N.; Pucarevic, M.; Strbac, S.; Chemosphere 2019, 229, 324.

8. Bolaji, B. B.; Francis, D. S.; Ibitoruh, H.; Challenges 2015, 6, 244. 
9. Zorer, Ö. S.; Microchem. J. 2019, 145, 762.

10. Yantasee, W.; Fryxell, G. E.; Pattamakomsan, K.; Sangvanich, T.; Wiacek, R. J.; Busche, B.; Addleman, R. S.; Timchalk, C.; Ngamcherdtrakul, W.; Siriwona, N.; J. Hazard. Mater. 2019, 366, 677.

11. Ramírez-De la Cruz, F. de M.; Iturbe-García, J. L.; Ordoñez-Regil, E.; Rev. Soc. Quím. Méx. 1990, 34(1), 27.

12. Fetter, N.; Blichert-Toft, J.; Ludden, J.; Lepland, A.; Sánchez-Borque, J.; Greenhalgh, E.; García, B.; Edwards, D.; Télouk, P.; Albarède, F.; Earth Planet. Sci. Lett. 2019, 525, 115738.

13. Baeza, A.; Salas, A.; Guillén, J.; Muñoz-Serrano, A.; Corbacho, J. A.; J. Hazard. Mater. 2019, 371, 586.

14. Heldal, H. E.; Volynkin, A.; Komperod, M.; Hannisdal, R.; Skjerdal, H.; Rudjord, A. L.; J. Environ. Radioact. 2019, 205-206, 42.

15. Rosa, M. M. L.; Maihara, V. A.; Taddei, M. H. T.; Dias, F. F.; Nuclear Conference - INAC, 2009, ISBN 978-85-99141-03-8.

16. Li, X.; Sun, S.; Hu, X.; Huang, H.; Li, H.; Morino, Y.; Wang, S.; Yang, X.; Shi, J.; Fang, S.; J. Hazard. Mater. 2019, 379, 120770.

17. Sarin, M. M.; Brushan, R.; Rengarajan, R.; Yadav, D. N.; Indian J. Mar Sci. 1992, 21, 121.

18. Lariviere, D.; Taylor, V. F.; Evans, R. D.; Cornett, J.; Spectrochim. Acta, Part B 2006, 61, 877.

19. Becker, J. S.; Spectrochim. Acta, Part B 2003, 58, 1757.

20. Pedreira, W. R., Sarkis, J. E. S., Da Silva Queiroz, C. A., Rodrigues, C., Tomiyoshi, I. A., Abra oa, A.; J. Solid State Chem. 2003, 171, 3.

21. Wysocka, I., Vassileva, E.; Anal. Chim. Acta 2018, 1000, 144.

22. Fischera, L., Smith, G., Hanna, S., Bruland, K. W.; Marine Chem. 2018 , 199, 44.

23. Water \& Environment Newsletter No. 34, ISSN-1020-7120, 2018, available at http://www.iaea.org/water, accessed in November 2021.

24. United Nations, available at https://www.un.org/en/sections/issuesdepth/water/, accessed in November 2021.

25. Modificación a la Norma Oficial Mexicana NOM-127-SSA1-1994, Salud ambiental. Agua para uso y consumo humano. Límites permisibles de calidad y tratamientos a que debe someterse el agua para su potabilización, available at http://www.salud.gob.mx/unidades/cdi/nom/ m127ssa14.html, accessed in November 2021.

26. World Health Organization (WHO); Guidelines for Drinking-water Quality, WHO Library Cataloguing-in-Publication Data Guidelines for drinking-water quality, $4^{\text {th }}$ ed., World Health Organization. 2011, ISBN 978924154815 , pp. 1.

27. Sheppard, S. C.; Sheppard, M. I.; Ilin, M.; Tait, J.; Sanipelli, B.; J. Environ. Radioact. 2008 99, 933.
28. Romero-Guzmán, E. T.; Hernández-Mendoza, H.; Reyes-Gutiérrez, L. R.; Ríos-Lugo, M. J.; Hernández-Santana, J.; Journal of Nuclear Physics, Material Sciences, Radiation and Applications 2016, 4, 159.

29. Suárez-Navarro, J. A.; Pujol, L. L.; Suarez-Navarro, M. J.; Appl. Radiat. Isot. 2017, 130, 162.

30. Norma Oficial Mexicana NOM-014-SSA1-1993 "Procedimientos sanitarios para el muestreo de agua para uso y consumo humano en sistemas de abastecimiento de agua públicos y privados", available at http://www.salud.gob.mx/unidades/cdi/nom/014ssa13.html, accessed in November 2021.

31. USEPA; Microwave assisted acid digestion of aqueous samples and extracts, EPA method 3015A, 2019, available at https://www.epa. gov/sites/production/files/2015-12/documents/3015 a.pdf, accessed in November 2021.

32. National Institute of Standards \& Technology; Certificate of Analysis Standard Reference Material ${ }^{\circledR} 1640$ a Trace Elements in Natural Water, SRM 1640a, pp. 1-6.

33. Pérez B. M. A.; Romero, G. E. T.; Identification del Plan de validación, PL.VL.LNF.05-2018, pp. 1

34. Holden, N. E.; Coplen, T. B.; Böhlke, J. K.; Tarbox, L. V.; Benefield, J.; De Laeter, J. R.; Mahaffy, P. G.; O'Connor, G.; Roth, E.; Tepper, D. H.; Walczyk, T.; Wieser, M. E.; Yoneda, S.; IUPAC Periodic Table of the Elements and Isotopes (IPTEI) for the Education Community - Update 2019 (IUPAC Technical Report), 260 p., available at https://iupac.org/ iptei, accessed in November 2021.

35. Reimann, C.; Smith, D. B.; Woodruff, L. G.; Flem, B.; Appl. Geochem. 2011, 26, 1623.

36. Kurpiel, R.; Pickering, R.; Maas, R.; Stern, N.; Journal of Archaeological Science: Reports 2019, 23, 62.

37. Raedera, S.; Heggena, H.; Teigelhöfera, A.; Lassena, J.; Spectrochim. Acta, Part B 2019, 151, 65

38. Why do all radioactive decay series terminate at lead?, available at https://chemistry.stackexchange.com/questions/42922/why-do-allradioactive-decay-series-terminate-at-lead, accessed in November 2021.

39. Nuclear Energy in the 21st Century, 2007, p.155, APPENDIX 2. Some radioactive decay series showing half-lives, https://doi.org/10.1016/ B978-012373622-2/50014-3.

40. Radioactive series, 2021, available at https://www.chegg.com/learn/ physics/introduction-to-physics/radioactive-series, accessed in November 2021.

41. Kleinschmidt, R.; Akber, R.; J. Environ. Radioact. 2008, 99, 607.

42. Lide, D. R.; J. Am. Chem. Soc. 2004, 126, 1586. 